九州大学学術情報リポジトリ

Kyushu University Institutional Repository

\title{
Immobilization of alkaline phosphatase on magnetic particles by site-specific and covalent cross-linking catalyzed by microbial transg lutaminase
}

Mor i yama, Kousuke

Department of Applied Chemistry, Graduate School of Engineering, Kyushu University

Sung, Kyunga

Department of Applied Chemistry, Graduate School of Engineering, Kyushu University

Goto, Masahiro

Center for Future Chemistry, Kyushu University | Department of Applied Chemistry, Graduate School of Engineering, Kyushu University

Kamiya, Noriho

Center for Future Chemistry, Kyushu University

http://hdl. handle. net/2324/25516

出版情報: Journal of Bioscience and Bioengineering. 111 (6)，pp.650-653，2011-06. Elsevier バージョン :

権利関係: (C) 2011 The Society for Biotechnology, Japan. 
Submitted to Journal of Bioscience and Bioengineering (Note)

Immobilization of bacterial alkaline phosphatase on magnetic particles by site-specific and covalent cross-linking catalyzed by microbial transglutaminase

\author{
Kousuke Moriyama ${ }^{1}$, Kyunga Sung ${ }^{1}$, Masahiro Goto ${ }^{1,2}$, and Noriho Kamiya ${ }^{2 *}$ \\ ${ }^{1}$ Department of Applied Chemistry, Graduate School of Engineering, Kyushu University, 744 \\ Motooka, Fukuoka 819-0395, Japan \\ ${ }^{2}$ Center for Future Chemistry, Kyushu University, 744 Motooka, Fukuoka 819-0395, Japan
}

RUNNING TITLE: Protein immobilization on magnetic particles

*Corresponding author:

E-mail: nori_kamiya@mail.cstm.kyushu-u.ac.jp

Tel: $+81-92-802-2807$

Fax: $+81-92-802-2810$ 
Bacterial alkaline phosphatase (BAP) was site-specifically and covalently immobilized on magnetic particles (MPs) using the enzymatic reaction of microbial transglutaminase (MTG). Immobilization efficiency was affected by the chemical surface treatment of MPs and immobilized BAP exhibited more than $90 \%$ of the initial activity after 10 rounds of recycling.

[Keywords: magnetic particles; site-specific and covalent immobilization; microbial transglutaminase]

Magnetic particles (MPs) have received a significant amount of attention because of their potential use in various biotechnological applications, including protein and enzyme immobilization, agents in magnetic resonance imaging (MRI), separation and sorting proteins and cells, drug delivery system, hyperthermia treatment for cancerous tumors and immunoassays (1-3). A major advantage of MPs is the easy and rapid recovery of target molecules from the reaction mixture. The performance of MPs is significantly affected by surface modifications. Various molecules are immobilized on MPs by suitable surface modifications. Thus, using MPs as a support for enzyme immobilization is important for biocatalysts.

Carrier bound immobilized enzymes on a fabricated solid surface is a convenient and useful industrial biocatalyst design. Enzyme immobilization simplifies the bioreactor design and enables the recycling of the catalyst as long as the immobilized enzyme maintains its functional tertiary structure. Immobilization methods that use physical adsorption and chemical techniques have been presented; however, enzymes often become inactive upon immobilization due to protein denaturation (4). Consequently, enzymatic methods for site-specific and covalent immobilization of 
recombinant proteins have attracted attention in recent years. In this approach, a reactive peptide or protein tag is introduced to the target protein (5-7). Since this peptide or protein tag is combined with functional groups on the modified solid support, it is expected that the target enzyme attached to the surface maintains functionality, because it is not directly involved in the attachment process. Since enzymes exhibit high substrate specificity and the catalytic reaction often proceeds under mild conditions, using enzymes to specifically immobilize proteins to a surface is considered a useful strategy that should not disrupt the intrinsic function of the tethered enzyme. We have focused on the capability of microbial transglutaminase (MTG) in the protein immobilization reaction. MTG is a unique enzyme that catalyzes an acyl transfer reaction between the $\gamma$ carboxyamide groups of glutamines (acyl-donors) in proteins and peptides as well as various primary amines (acyl-acceptors), including the amino groups of lysine residues (8). It has been demonstrated that the simple introduction of a substrate peptide tag to recombinant proteins promotes the site-specific and covalent immobilization of the enzyme onto modified plastic plates and resin beads (9-12). In this paper, we extended our strategy to the surface functionalization of inorganic particulate formulation for the first time. Namely, the immobilization of Escherichia coli bacterial alkaline phosphatase (BAP) fused with a substrate peptide, MLAQGS, at the C-terminus (CQ6-tag (11)) on MPs displaying primary amines was conducted by MTG catalysis (Figure 1A), and the enzymatic activity of immobilized BAP was evaluated.

CQ6-tag fused recombinant BAP (abbreviated as CQ6-BAP) was prepared according to the procedure described previously (11). MPs modified with primary amines were purchased from Bangs Laboratories, Inc. (Fishers, Indiana, USA; magnetic core: magnetite $\left(\mathrm{Fe}_{3} \mathrm{O}_{4}\right)$; coating matrix: 
silica; mean diameter: $1.5 \mu \mathrm{m}$; surface area: $100 \mathrm{~m}^{2} / \mathrm{g}$ ). The surface of the MPs was modified with diethyleneglycol bis(3-aminopropyl)ether (DGBE) (Tokyo Chemical Industry Co. Ltd., Tokyo) (Figure 1B). Initially, MPs were placed in a $0.5 \mathrm{M}$ solution of succinic anhydride in DMF for $12 \mathrm{~h}$ at $\sim 24{ }^{\circ} \mathrm{C}$ with gentle shaking. After washing with DMF, the MPs were soaked in a $0.5 \mathrm{M} N, N^{\prime}-$ dimethyl-carbodiimide (DIC), $0.5 \mathrm{M} \mathrm{N}$-hydroxysuccinimide (NHS) solution in DMF for $6 \mathrm{~h}$ at $\sim 24{ }^{\circ} \mathrm{C}$ with gentle shaking. After washing with DMF, MPs were soaked in a $1 \mathrm{M}$ DGBE, $1 \mathrm{M}$ ethanolamine (EA) solution in DMF (DGBE:EA volume ratios of 100:0, 80:20, 50:50, 20:80 and 5:95) for $6 \mathrm{~h}$ at $\sim 24^{\circ} \mathrm{C}$ with gentle shaking. Finally, $1 \mathrm{M}$ EA was added for inactivation of active esters that were not modified with DGBE, and the chemically modified MPs were washed with DMF and Milli-Q water (Figure 1A).

Immobilization experiments were performed by mixing $1 \mathrm{mg}$ of chemically modified MPs with a CQ6-BAP $(0.1 \mathrm{mg} / \mathrm{ml})$ in $1 \mathrm{ml}$ Tris-HCl buffer $(10 \mathrm{mM}, \mathrm{pH} 8.0)$ in the presence or absence of MTG $(0.5 \mathrm{U} / \mathrm{ml})$ for $6 \mathrm{~h}$ at $\sim 24{ }^{\circ} \mathrm{C}$ with gentle shaking. Following immobilization, MPs were washed with TBS, $0.01 \%$ Tween-20 and $1 \mathrm{M} \mathrm{NaCl}$ solutions three times, respectively. Wild-type recombinant BAP without the CQ6-tag (Wako Pure Chemical, Osaka) was used as a control.

The catalytic activity of immobilized BAP was evaluated with $1 \mathrm{mM}$-nitrophenyl phosphate ( $p$ NPP) in $1 \mathrm{M}$ Tris- $\mathrm{HCl}$ buffer $(\mathrm{pH} 8.0)$ at room temperature $\left(\sim 24^{\circ} \mathrm{C}\right)$. The enzymatic activity of BAP was determined by measuring the absorbance at $410 \mathrm{~nm}$ of the hydrolyzed product, $p$ nitrophenol, using a plate reader (Power Wave X, Bio-Tec Instruments Inc., USA). After being mixed vigorously for 2 min with a mixer (EYELA CM-1000, Tokyo Rikakikai Co., Ltd., Japan ) to allow the reaction to proceed, MPs were magnetically separated from the solution using a 
neodymium magnet (Sangyo Supply Co., Ltd., Miyagi, Japan), and the absorbance of the remaining solution was measured. The catalytic activity data were collected and expressed as the average value of three independent measurements.

Firstly, we attempted the immobilization of CQ6-BAP on the original amine-modified MPs without DGBE modification. However, physical adsorption of CQ6-BAP was dominant (data not shown). Therefore, MPs were modified with DGBE to suppress the non-specific adsorption of CQ6-BAP. Wild-type BAP was first applied to the DGBE-modified MPs in the presence of MTG. The observed activity was only $7.3 \%$ when compared to the activity of MPs-immobilized CQ6BAP prepared using MTG. In addition, low activity of CQ6-BAP was observed in the absence of MTG, suggesting that physical adsorption of BAP was substantially suppressed by the surface modification with DGBE (Fig. 1C). These results show that a peptide tag including a Gln residue is recognized by MTG and the reaction proceeds actively on the DGBE-modified MPs. The activity of immobilized BAP under different DGBE:EA volume ratios is presented in Figure 1D. In the presence of MTG, immobilized BAP under DGBE:EA volume ratios of 100:0 and 80:20 exhibited the same degree of activity; however the activity rapidly decreased with decreasing DGBE volume ratios. The quantity of immobilized BAP appears to decrease with decreasing accessible primary amines as the MTG substrate on the MPs. On the other hand, immobilized BAP showed comparable activities in all conditions in the absence of MTG. This implies that physical adsorption of CQ6-BAPs was suppressed at the same levels by the modification with hydrophilic molecules such as DGBE and EA on the surface of MPs. An important factor on MTG-mediated site-specific protein immobilization is to suppress physical adsorption of proteins. Surface modification with 
poly(ethylene glycol) (PEG) has been shown to be effective in inhibition of protein adsorption. In this study, the physical adsorption of CQ6-BAP on the MPs was likely to be diminished by the modification with DGBE including PEG chain.

We next examined the immobilization amounts of BAP on DGBE modified MPs as a function of the CQ6-BAP concentration. The concentrations of MPs (DGBE:EA volume ratios of 80:20) and MTG were fixed at $1 \mathrm{mg} / \mathrm{ml}$ and $0.5 \mathrm{U} / \mathrm{ml}$, respectively. The CQ6-BAP concentration was varied in the range of $0.01-0.5 \mathrm{mg} / \mathrm{ml}$. After immobilization, the activity of immobilized BAP was measured with p-NPP. Figure 2 depicts the relationship between the equilibrium concentration of CQ6-BAP in the reaction solution and the amount of immobilized CQ6-BAP. When the initial CQ6-BAP concentration was at $0.5 \mathrm{mg} / \mathrm{ml}$, immobilization capacity was $0.66 \mathrm{pmol}-\mathrm{CQ} 6-\mathrm{BAP} / \mathrm{cm}^{2}-\mathrm{MPs}$, and the amount of immobilized BAP continued to increase beyond its concentration. Given that the immobilization system follows chemisorptions, the collected data were fitted to the Langmuir adsorption isotherm:

$$
\mathrm{q}=\mathrm{q}_{\mathrm{m}} \mathrm{K}[\mathrm{CQ6}-\mathrm{BAP}] /(1+\mathrm{K}[\mathrm{CQ6}-\mathrm{BAP}])
$$

where $\mathrm{q}$ is the immobilization density of CQ6-BAP and $\mathrm{q}_{\mathrm{m}}$ is maximum immobilization density. The data fitting was carried out using the Origin7 software on a personal computer (solid line in Figure 2). The maximum immobilization density of CQ6-BAP was estimated to be 0.98 pmolCQ6-BAP $/ \mathrm{cm}^{2}$-MPs. For further analysis, primary amino groups on the DGBE-modified MPs were quantified with Sulfo-LC-SPDP (Sulfosuccinimidyl 6-(3'-[2-pyridyldithio]propionamido)hexanoate, Pierce Chemicals, Rockford, IL, USA) according to the reported 
procedure (13). As a result, the number of primary amino groups was estimated to be 18.5 pmol$\mathrm{NH}_{2} / \mathrm{cm}^{2}$-MPs. The results suggest that only $5.3 \%$ of the primary amino groups on the surface of the MPs were occupied by CQ6-BAP at the maximum loading. Although, an excess amount of DGBE (1M DGBE) was applied in the surface modification process, it is likely that the DGBEmodified MPs bear a small number of accessible primary amino groups available for MTG catalysis.

Since the reusability of immobilized proteins has economic benefits, we repeatedly assayed the immobilized CQ6-BAP activity. Following immobilization, the activity of immobilized BAP was measured with p-NPP as mentioned before. After the activity measurement of BAP, the CQ6-BAP immobilized MPs (1 mg) were magnetically recovered, washing with $1 \mathrm{M} \mathrm{NaCl}$ solution (400 $\mu \mathrm{l})$, then used for the next assay. As shown in Figure 3, repeated use of CQ6-BAP immobilized MPs showed $93 \%$ of the initial activity after ten rounds of operation, suggesting the stable covalent immobilization of CQ6-BAP. Since non-enzymatic immobilization of CQ6-BAP on the DGBEmodified MPs was observed (bars of MTG(-) in Fig. 1C and 1D), the slight decrease of enzymatic activity after ten rounds of operation may be due to the gradual desorption of non-specifically adsorbed CQ6-BAP from the MPs surface.

In conclusion, using the combination of a substrate peptide tag-fused to the target protein, primary amine-modified MPs (DGBE-modified MPs) and MTG catalysis, a recombinant enzyme (CQ6BAP) was site-specifically and covalently immobilized on MPs via the substrate peptide tag. The immobilized BAP retained more than $90 \%$ of the initial activity after ten rounds of assaying the activity of the tethered CQ6-BAP. The results show the potential for the applicability of the present 
system to immobilize various recombinant proteins on MPs. Further validation of the established methodology on nano-sized materials is in progress in our group.

\section{ACKNOWLEDGMENTS}

We are grateful to Ajinomoto Co., Inc. (Japan), for providing MTG samples. This work was supported by a Grant-in-Aid for the Global COE program "Science for Future Molecular Systems", from the Ministry of Education, Culture, Sports, Science and Technology of Japan.

\section{References}

1. Yu, C. C., Lin, P. C., Lin, C. C.: Site-specific immobilization of CMP-sialic acid synthetase on magnetic nanoparticles and its use in the synthesis of CMP-sialic acid, Chem Commun., 1308-1310 (2008).

2. Morozov, V. N., Groves, S., Turell, M. J., Bailey, C.: Three minutes-long electrophoretically assisted zeptomolar microfluidic immunoassay with magnetic-beads detection, J. Am. Chem. Soc., 129, 12628-12629 (2007)

3. Laurent, S., Forge, D., Port, M., Roch, A., Robic C., Elst, L. V., Muller, R. N.: Magnetic iron oxide nanoparticles: synthesis, stabilization, vectorization, physicochemical characterizations, and biological applications, Chem. Rev., 108, 2064-2110 (2008) 
4. Wong, L. S., Khan, F., Micklefield, J.: Selective covalent protein immobilization: strategies and applications, Chem. Rev., 109, 4025-4035 (2009).

5. Hondneland, C. D., Lee, Y. S., Min. D. H., Mrksich, M.: Selective immobilization of proteins to self-assembled monolayers presenting active site-directed capture ligands, Proc. Natl. Acad. Sci. USA. 99, 5048-5052 (2002).

6. Wong, L. S., Thirlway, J., Micklefield, J.: Direct site-selective covalent protein immobilization catalyzed by a phosphopantetheinyl transferase, J. Am. Chem. Soc., 130, 12456-12464 (2008)

7. Sung, K., Kamiya, N., Kawata, N., Kamiya, S., Goto, M.: Functional glass surface displaying a glutamyl donor substrate for transglutaminase-mediated protein immobilization, Biotechnol. J., 5, 456-462 (2010)

8. Yokoyama, K., Nio, N., Kikuchi, Y.: Properties and application of microbial transglutaminase. Appl. Micobiol. Biotechnol. 64, 447-454 (2004).

9. Kamiya, N., Doi, S., Tominaga, J., Ichinose, H., Goto, M.: Transglutaminase-mediated protein immobilization to casein nanolayers created on a plastic surface, Biomacromolecules., 6, 35-38 (2005).

10. Tominaga, J., Kamiya, N., Doi, S., Ichinose, H., Goto, M.: An enzymatic strategy for sitespecific immobilization of functional proteins using microbial transglutaminase, Enzyme Microb Technol., 35, 613-618 (2004). 
11. Kamiya, N., Doi, S., Tanaka, Y., Ichinose, H., Goto, M.: Functional immobilization of recombinant alkaline phosphatases bearing a glutamyl donor substrate peptide of microbial transglutaminase, J. Biosci. Bioeng., 104, 195-199 (2007).

12. Sugiyama, Y., Ueda, H., Maki, M., Hitomi, K.: Novel site-specific immobilization of a functional protein using a preferred substrate sequence for transglutaminase 2, J. Biotechnol., 131, 121-127 (2007).

13. Yoza, B., Arakaki, A., Maruyama, K., Takeyama, H., Matsunaga, T.: Fully automated DNA extraction from blood using magnetic particles modified with a hyperbranched polyamidoamine dendrimer, J. Biosci. Bioeng., 95, 21-26 (2003). 


\section{FIGURE LEGENDS}

Figure 1. (A) Schematic illustration of site-specific and covalent immobilization of a recombinant protein tagged with a Gln-containing substrate peptide on chemically modified MPs. (B) Preparation procedures of DGBE-modified MPs. (C, D) Comparison of the enzymatic activity of immobilized BAP on DGBE-modified MPs: (C) The immobilization of recombinant BAP with or without the CQ6-tag. All experiments were conducted with MPs under a DGBE:EA volume ratio of 100:0. (D) The immobilization of CQ6-BAP under different DGBE:EA volume ratios.

Figure 2. The effect of the concentration of CQ6-BAP on immobilization. The solid line in the figure represents Langmuir adsorption isotherm fit $(\mathrm{R}=0.993)$ to the experimental data.

Figure 3. Enzymatic activity of MPs-CQ6-BAP as a function of repetitive use. 
A

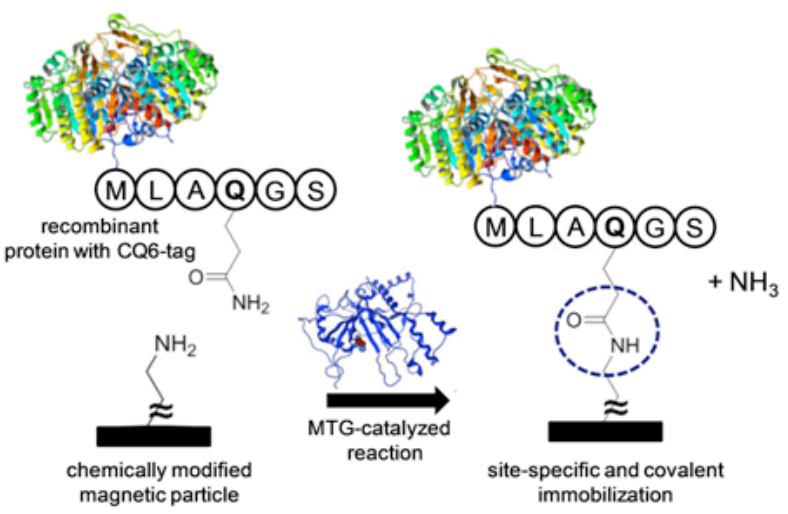

C

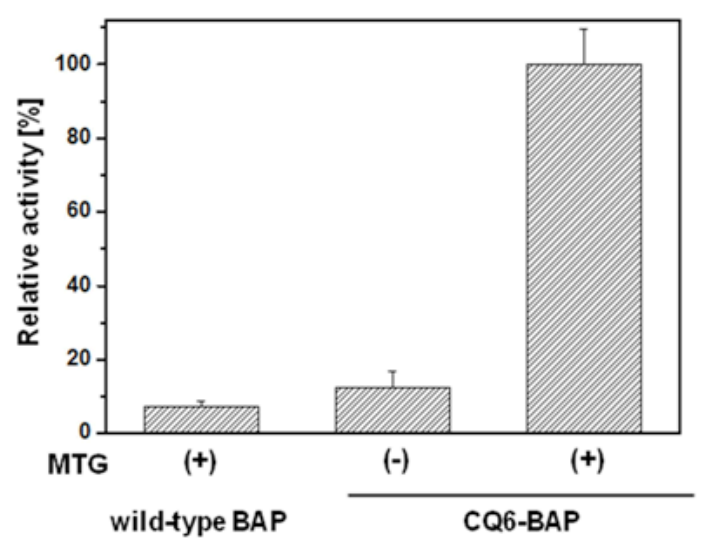

B

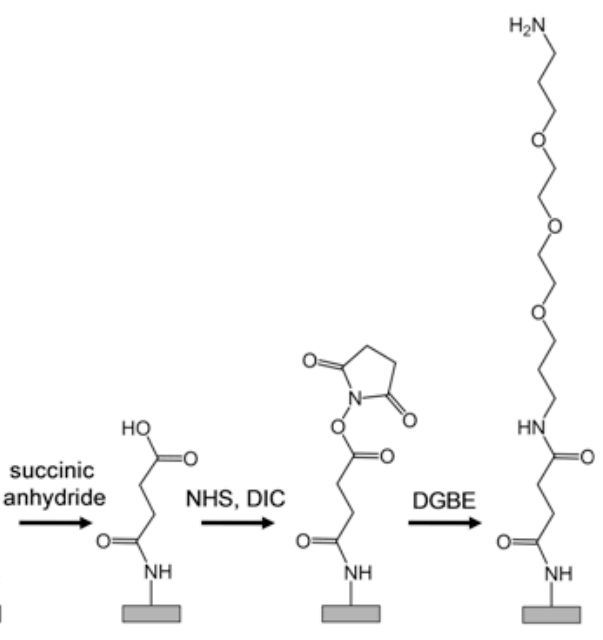

D

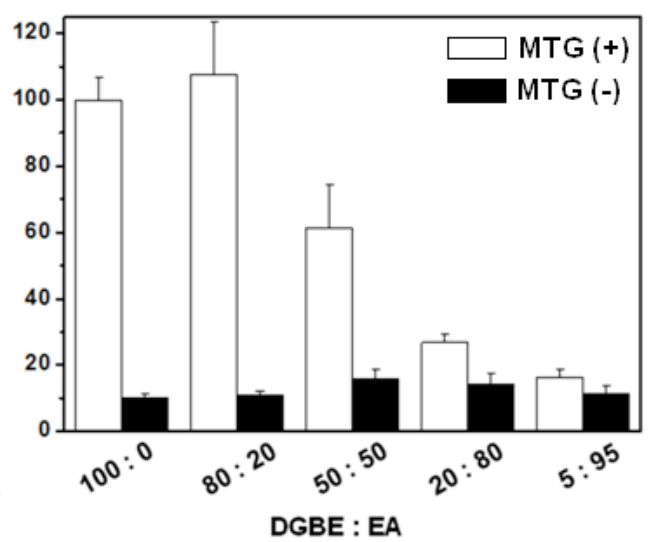

Figure 1 


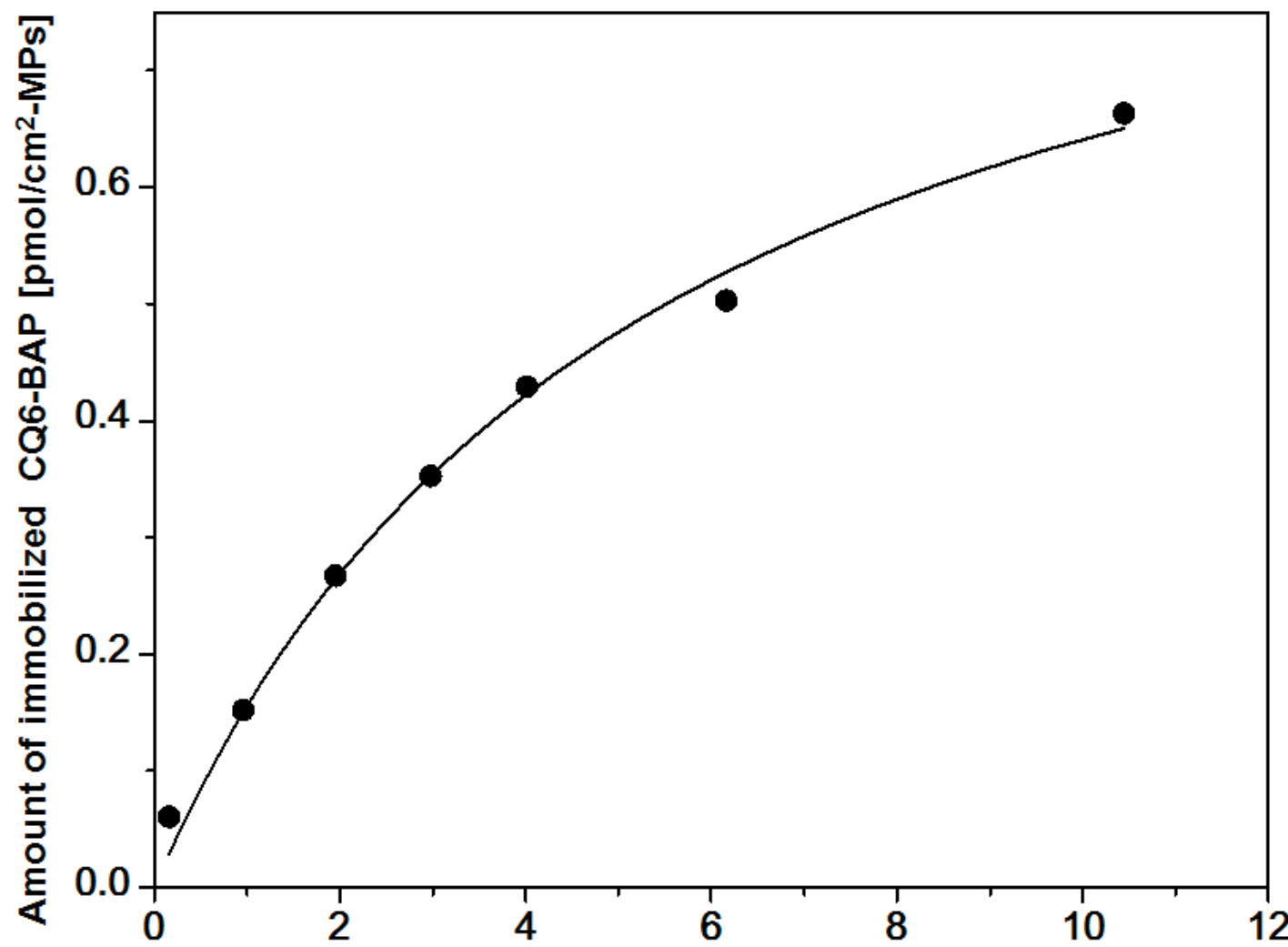

Equilibrium concentration of CQ6-BAP in the solution $[\mu \mathrm{M}]$

Figure 2 


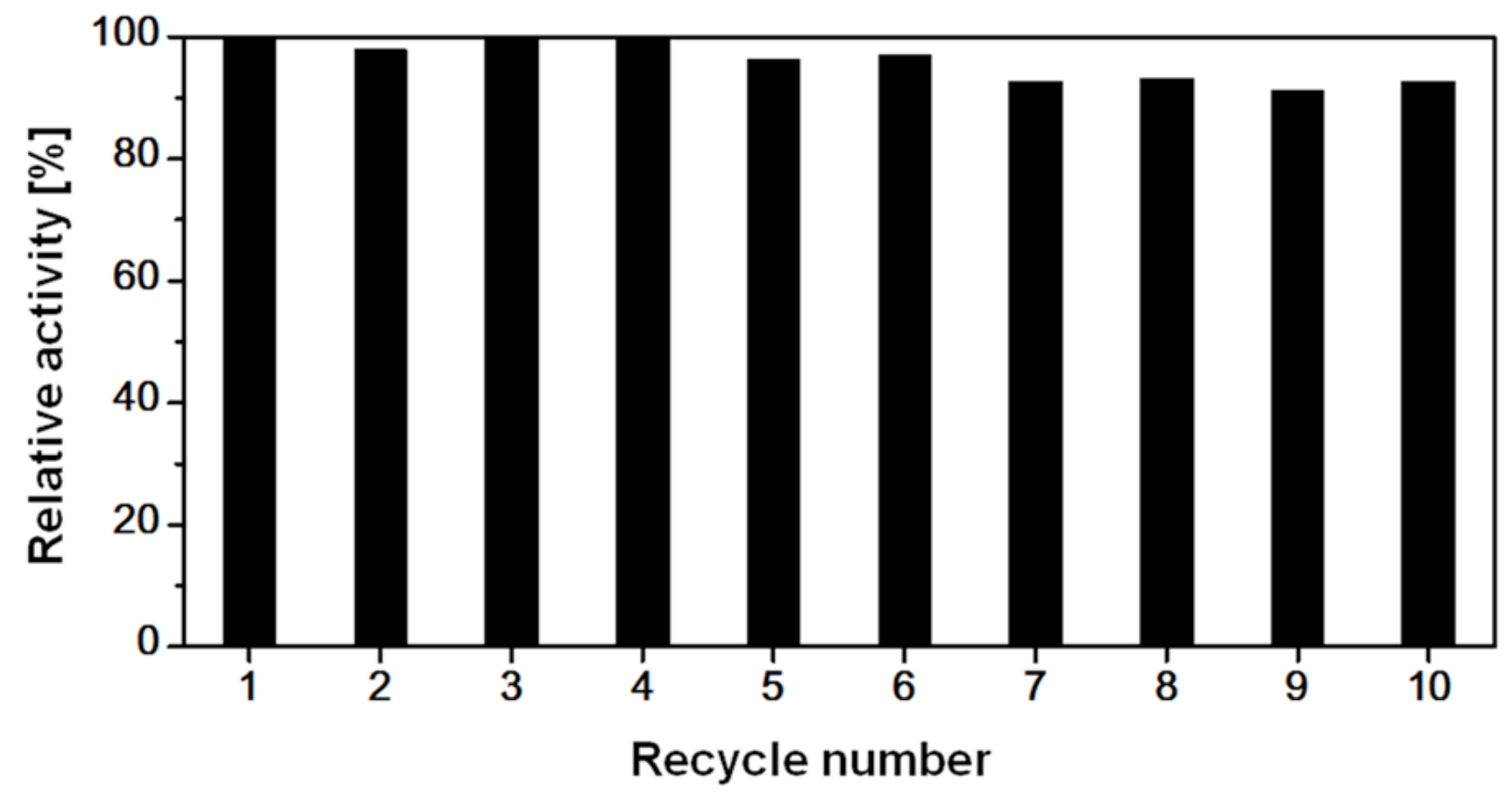

Figure 3 